\title{
Downregulation of miR-138-5p promotes non-small cell lung cancer progression by regulating CDK8
}

\author{
SHIGANG XING ${ }^{1}$, QINGHUA XU ${ }^{1}$, XINLEI FAN ${ }^{2}$, SHANXIA WU $^{3}$ and FENG TIAN ${ }^{4}$ \\ ${ }^{1}$ Department of Respiratory Medicine, The Central Hospital of Linyi, Linyi, Shandong 276400; \\ ${ }^{2}$ Department of Internal Medicine, Shandong Medical College; ${ }^{3}$ Department of Vasculocardiology, \\ The Third People's Hospital of Linyi; ${ }^{4}$ Department of Respiratory Medicine, Linyi People's Hospital, \\ Linyi, Shandong 276000, P.R. China
}

Received June 25, 2018; Accepted July 8, 2019

DOI: $10.3892 / \mathrm{mmr} .2019 .10741$

\begin{abstract}
Dysregulation of microRNAs (miRNAs) is frequently observed during cancer development. Aberrant expression of miRNA-138-5p (miR-138-5p) has been found in many types of cancer. However, the role and the mechanisms underlying miR-138-5p function in non-small cell lung cancer (NSCLC) progression remain unknown. In the present study, miR-138-5p expression was identified to be decreased in tumor tissues compared with matched normal tissues from patients with NSCLC. In addition, low expression of miR-138-5p was detected in three NSCLC cell lines compared with a normal lung epithelium cell line. Moreover, CDK8 mRNA expression was increased in tumor tissues compared with matched normal tissues from patients with NSCLC, and an inverse association between miR-138-5p and CDK8 was observed. Furthermore, CDK8 was predicted to be a target of miR-138-5p. Dual luciferase assay confirmed that miR-138-5p could directly bind to the 3' untranslated region of CDK8 mRNA. In A549 cells, overexpression of miR-138-5p inhibited cell growth and significantly increased cell apoptosis rates and the number of cells in G0/G1 phase. Moreover, forced overexpression of CDK8 partially reversed miR-138-5p mimic-induced cell growth arrest and alteration of cell apoptosis and cell cycle. In conclusion, the present results suggested that miR-138-5p may be a tumor suppressor in NSCLC cells and a promising therapeutic target for treating patients with NSCLC.
\end{abstract}

\section{Introduction}

Lung cancer is one of most lethal cancer types worldwide with an estimate of 1.8 million new cases and 1.5 million mortalities in 2012 (1). As a major subtype of lung cancer, non-small cell

Correspondence to: Dr Feng Tian, Department of Respiratory Medicine, Linyi People's Hospital, 2 Wuhan Road, Linyi, Shandong 276000, P.R. China

E-mail: tianfenglyph@126.com

Key words: microRNA-138-5p, non-small cell lung cancer, CDK8 lung cancer (NSCLC) accounted for $>80 \%$ of all lung cancer cases (2). Although development of concomitant chemoradiotherapy has improved patient outcome, patients with NSCLC can develop resistance, reducing the 5-year survival rate to $\sim 30 \%$ (3). Therefore, further investigation of the molecular mechanism driving NSCLC cell proliferation is required in order to develop new effective therapeutic approaches to improve NSCLC patient survival.

MicroRNAs (miRNAs) are small, non-coding, single-stranded RNA molecules that are ubiquitously expressed in various types of cells (4). Mechanistically, miRNAs can bind to the 3 ' untranslated region (UTR) of multiple target genes, thus inducing mRNA degradation or translational inhibition (5). By regulating expression of multiple genes, miRNAs are involved in many physiological processes including cell proliferation, differentiation, cell cycle and metastasis (6). Accumulating evidences showed that miRNA dysregulation is responsible for cancer initiation and progression (7). In NSCLC, using microarray analysis, 15 differentially expressed miRNAs were identified between normal lung and squamous cell carcinoma, one subtype of NSCLC, and these miRNAs were proved to be good predictors of patient survival (8). Downregulation of miR-138-5p was first identified in human anaplastic thyroid carcinoma cells and was found to regulate cell proliferation by targeting telomerase reverse transcriptase (9). A previous study showed that downregulation of miR-138-5p is involved in the development of many cancer types $(10,11)$. A previous study identified that miR-138-5p is pivotal for gefitinib sensitivity in NSCLC cells (12). However, little is known about the role of miR-138-5p in mediating NSCLC cell proliferation and survival.

Cyclin-dependent kinases (CDKs) form complexes with cyclins to regulate cell cycle progression in human cells, which is maintained by the tight control of CDK activity (13). In cancer cells, aberrant expression of CDKs causes an accelerated cell cycle, leading to uncontrolled cell proliferation (14). Among the CDK family members, various studies observed that CDK8 is upregulated in cancer cells and may represent a promising target for cancer therapy (15). Interestingly, the mechanism underlying CDK8 overexpression remains unclear.

In the present study, a decrease in miR-138-5p was observed in NSCLC tumor tissues compared with normal tissues. Reverse transcription-quantitative PCR (RT-qPCR) and western blot 
analysis suggested that CDK8 was regulated by miR-138-5p in A549 cells. Furthermore, CDK8 was identified as a target gene of miR-138-5p. In addition, miR-138-5p overexpression inhibited A549 cell growth, leading to cell apoptosis and accumulation of cells in G0/G1 phase. Notably, the effect of miR-138-p could be reversed by CDK8 overexpression.

\section{Materials and methods}

Patient samples. Tumor tissues and matched normal tissues were collected from 30 patients with NSCLC (17 males and 13 females; age, 62. 21 \pm 5.23 years) in The Central Hospital of Linyi between February 2015 and January 2016. Written consents were obtained from all participants. Ethical approval was obtained for the use of human tissues prior to the start of the study from an Ethics Committee based at The Central Hospital of Linyi. All tissues were subjected to RNA extraction.

Cell lines. Normal epithelial lung cell line BEAS-2B and the NSCLC cell lines A549, H358 and H1299 were purchased from The American Type Culture Collection and used within 6 months. All cell lines were maintained in RPMI-1640 medium (Gibco; Thermo Fisher Scientific, Inc.) supplemented with $10 \%$ FBS (HyClone; GE Healthcare Life Sciences) in a humidified incubator at $37^{\circ} \mathrm{C}$ with $5 \% \mathrm{CO}_{2}$.

Western blot analysis. Protein lysates were prepared using RIPA lysis buffer (Sigma-Aldrich; Merck KGaA) according to the manufacturer's protocol. The protein concentration was determined using the method bicinchoninic acid method. Antibodies for anti-CDK8 (cat. no 17395; dilution, 1:1,000) and $\beta$-catenin (cat. no 8480; dilution, 1:1,000) were purchased from Cell Signaling Technology, Inc. $\beta$-actin antibody (cat. no SAB5500001; dilution, 1:1,000) was bought from Sigma-Aldrich (Merck KGaA). Western blotting was performed as follows: Protein lysates $(20 \mu \mathrm{g})$ were loaded into each lane of a $10 \%$ SDS gel and separated by electrophoresis. The proteins were transferred to a PVDF membrane. After that, membranes were blocked at room temperature for $2 \mathrm{~h}$ using $5 \%$ non-fat milk followed by incubation with primary antibodies overnight at $4^{\circ} \mathrm{C}$. On the next day, the membranes were washed and incubated with the appropriate anti-rabbit horseradish peroxidase-conjugated secondary antibody (cat. no. 7074; 1:10,000; Cell Signaling Technology, Inc.) for $1 \mathrm{~h}$ at room temperature. The bands were visualized using an enhanced chemiluminescence (ECL) western blotting kit (Pierce; Thermo Fisher Scientific, Inc.). The quantification of bands was carried out using ImageJ (version 1.51; National Institutes of Health).

RNA extraction and RT- $q P C R$. RNA was extracted from cells or tissues using TRIzol (Invitrogen; Thermo Fisher Scientific, Inc.) according to the manufacturer's protocol. The RNA concentration was measured using a NanoDrop 2000 (Thermo Fisher Scientific, Inc.). For detection of miRNA expression, RNA was reverse transcribed into cDNA using the Mir-X miRNA First Strand Synthesis Kit (Takara Bio, Inc.) at $37^{\circ} \mathrm{C}$ for $1 \mathrm{~h}$ and $85^{\circ} \mathrm{C}$ for $5 \mathrm{~min}$. The RT-qPCR was performed using the Mir-X miRNA RT-qPCR SYBR kit (Thermo Fisher Scientific, Inc.) using the following thermocycling conditions: $95^{\circ} \mathrm{C}$ for $30 \mathrm{sec}$ followed by 40 cycles of $95^{\circ} \mathrm{C}$ for $5 \mathrm{sec}$ and $60^{\circ} \mathrm{C}$ for $30 \mathrm{sec}$. For
mRNA expression analysis, RNA was reverse transcribed into first strand cDNA using PrimeScript RT Master Mix (Takara Bio, Inc.) at $37^{\circ} \mathrm{C}$ for $15 \mathrm{~min}$ followed by $85^{\circ} \mathrm{C}$ for $5 \mathrm{sec} q \mathrm{PCR}$ with SYBR Premix Ex Taq II (Thermo Fisher Scientific, Inc.) was performed using the following thermocycling conditions: $95^{\circ} \mathrm{C}$ for $30 \mathrm{sec}$ followed by 40 cycles of $95^{\circ} \mathrm{C}$ for $5 \mathrm{sec}$ and $60^{\circ} \mathrm{C}$ for $30 \mathrm{sec}$. U6 and $\beta$-actin served as internal controls to normalize the expression of miRNAs and mRNAs, respectively. The primers used were the following: miR-138 forward, 5'-GGT GTCGTGGAGTCGGCAA-3' and reverse, 5'-AACTTCACA ACACCAGCTTA-3'; U6 forward, 5'-CTCGCTTCGGCAGCA CA-3' and reverse, 5'-AACGCTTCACGAATTTGCGT-3'; CDK8 forward, 5'-ACCTGTTTGAATACGAGGGCT-3' and reverse, 5'-TGCCGACATAGAGATCCCAGT-3'; and $\beta$-actin forward, 5'-CATGTACGTTGCTATCCAGGC-3' and reverse, 5'-CTCCTTAATGTCACGCACGAT-3'. Relative gene expression was analyzed using the $2^{-\triangle \Delta \mathrm{Cq}}$ method (16).

CDK8 overexpression. The full length of the open reading frame of CDK8 was amplified using Taq DNA polymerase (Invitrogen; Thermo Fisher Scientific, Inc.) from the cDNA of BEAS-2B (forward 5'-AAGCTTGGGCTCCGGCCTCAG AGGCT-3' and reverse, 5'-CTCGAGACCACATACAAAGAC AAATGCT-3') using the following thermocycling conditions: $94^{\circ} \mathrm{C}$ for $2 \mathrm{~min}$ followed by 35 cycles of $94^{\circ} \mathrm{C}$ for $2 \mathrm{sec}, 60^{\circ} \mathrm{C}$ for $60 \mathrm{sec}$ and $72^{\circ} \mathrm{C}$ for $1 \mathrm{~min}$. The product was digested with HindIII and XhoI and cloned into a pcDNA3.1 plasmid (Invitrogen; Thermo Fisher Scientific, Inc.). For CDK8 overexpression, pcDNA3.1-CDK8 $(2 \mu \mathrm{g})$ was transfected into A549 cells using Lipofectamine 3000 (Invitrogen; Thermo Fisher Scientific, Inc.) according to the manufacturer's protocol. The medium was changed after $8 \mathrm{~h}$ and the cells were cultured for a further $48 \mathrm{~h}$ prior to subsequent experiments.

Dual luciferase reporter assay. TargetScan (release 7.1, http://www.targetscan.org/vert_71/) was used to predict the interaction between miR-138-5p and CDK8 3'UTR. The 3'UTR of CDK8 was amplified using the Taq DNA polymerase (Invitrogen; Thermo Fisher Scientific, Inc.) from the cDNA of BEAS-2B (forward, 5'-GGTACCAAGGAGACAAAAAGAACC-3' and reverse, 5'-CTCGAGGTAGTGGTAGGAGGAACAAC-3') using the following thermocycling conditions: $94^{\circ} \mathrm{C}$ for $2 \mathrm{~min}$ followed by 35 cycles of $94^{\circ} \mathrm{C}$ for $2 \mathrm{sec}, 60^{\circ} \mathrm{C}$ for $60 \mathrm{sec}$ and $72^{\circ} \mathrm{C}$ for $1 \mathrm{~min}$. The product was ligated into pGL3 plasmid (Promega Corporation) between the KpnI and $\mathrm{Xhol}$ restriction enzyme sites. In total, two site mutations were introduced into pGL3-CDK8 3'UTR-wild-type (WT) to construct the pGL3-CDK8 3'UTR-mutant (Mut) plasmid using the Quick Site-directed Mutagenesis kit (Agilent Technologies, Inc.) using the following primers: Forward, 5'-GAGACAAAAAGAACGTGCAGCAGC AGCAGGG-3' and reverse, 5'-CCCTGCTGCTGCTGCACG TTCTTTTTGTCTC-3'. The following thermocycling conditions were used: $95^{\circ} \mathrm{C}$ for $30 \mathrm{sec}$ followed by 35 cycles of $95^{\circ} \mathrm{C}$ for $30 \mathrm{sec}, 55^{\circ} \mathrm{C}$ for $60 \mathrm{sec}$ and $78^{\circ} \mathrm{C}$ for $1 \mathrm{~min}$. In A549 cells, pGL3-CDK8 3'UTR-WT (0.4 mg) or pGL3-CDK8 3'UTR-Mut (0.4 mg) and miR-negative control (NC; 5'-UUGUACUACACA AAAGUACUG-3'; $20 \mathrm{nM}$ ) mimic or miR-138-5p mimic (5'-AGC UGGUGUUGUGAAUCAGGCCG-3'; $20 \mathrm{nM}$ ) were cotransfected into A549 cells using Lipofectamine ${ }^{\circledR} 3000$ (Invitrogen; Thermo Fisher Scientific, Inc.). After 24 h, the relative luciferase 
A

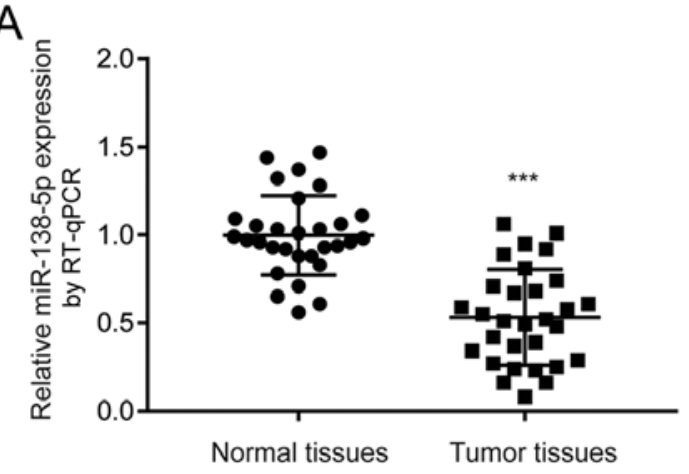

C

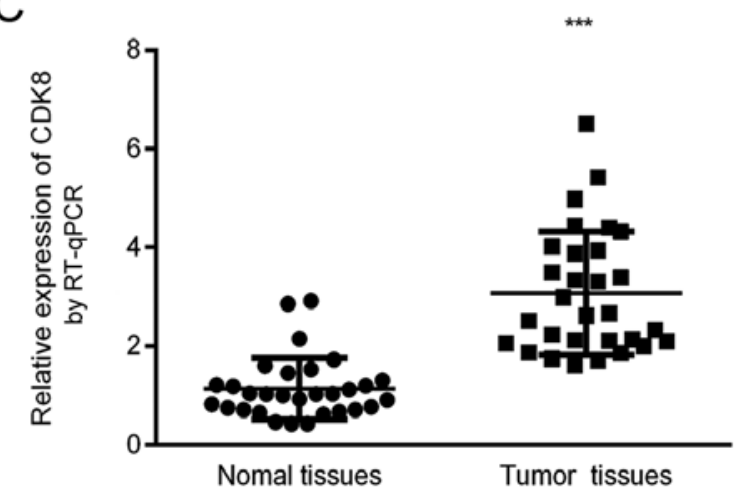

B

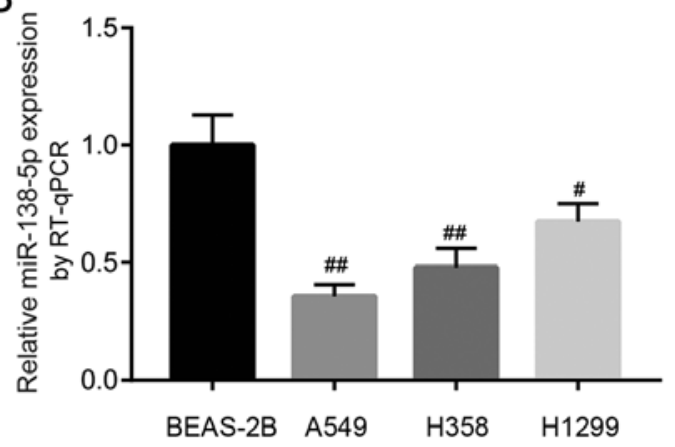

D

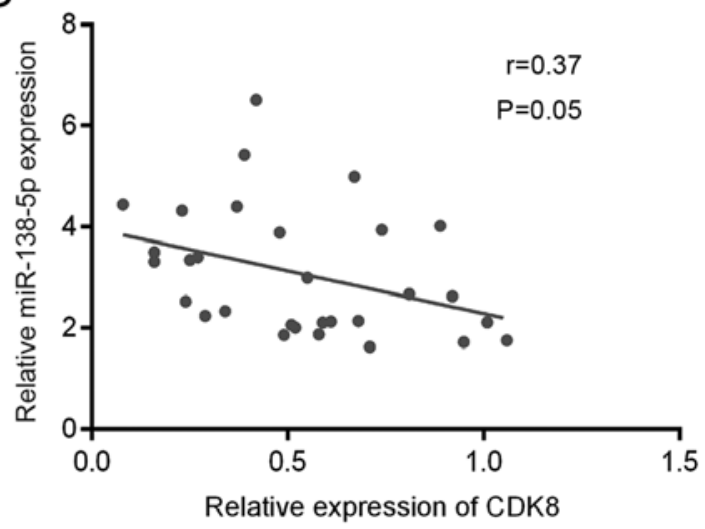

Figure 1. Downregulation of miR-138-5p in NSCLC tumor tissues and cell lines. (A) Compared with adjacent normal tissues, expression of miR-138-5p was decreased in tumor tissues isolated from patients with NSCLC. (B) In comparison with the normal lung epithelial cell line BEAS-2B, miR-138-5p levels were decreased in the NSCLC cell lines A549, H358 and H1299. (C) Compared with matched normal tissues, CDK8 mRNA expression was increased in tumor

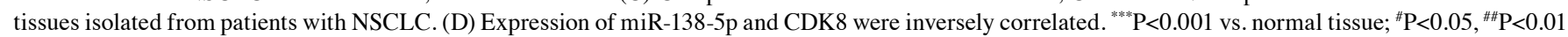
vs. BEAS-2B. miR, microRNA; NSCLC, non-small-cell lung carcinoma; RT-qPCR, reverse transcription-quantitative PCR.

activity in each well was measured using the dual-luciferase reporter assay system (Promega Corporation). Renilla luciferase activity was used for normalization.

Cell cycle and cell apoptosis analysis. For cell cycle analysis, cells $\left(1 \times 10^{5}\right.$ cells $\left./ \mathrm{ml}\right)$ were harvested and treated with $75 \%$ ethanol overnight at $4^{\circ} \mathrm{C}$. On the next day, cells were stained with propidium iodide (PI; Sigma-Aldrich; Merck KGaA). Cell cycle was then analyzed on a FACSCalibur flow cytometer (BD Biosciences). Cell apoptosis was detected using an Annexin V/PI apoptosis detection kit (Sigma-Aldrich; Merck KGaA). Briefly, cells were washed with PBS and resuspended in Annexin binding buffer. Subsequently, Annexin V-FITC and PI were added and incubated for $15 \mathrm{~min}$ at $4^{\circ} \mathrm{C}$. Cells were then subjected to flow cytometry analysis on a FACSCalibur flow cytometer (BD Biosciences). Cell cycle distribution and cell apoptotic rates were analyzed with FlowJo software (version 7.2; FlowJo LLC).

Cell proliferation assay. Cell proliferation was measured using a Cell Counting Kit-8 (CCK-8; Dojindo Molecular Technologies, Inc.). Briefly, 1,000 cells were plated in each well of a 96-well plate. After 24, 48 and 72 h, $10 \mu \mathrm{l} \mathrm{CCK-8} \mathrm{solution} \mathrm{was} \mathrm{added}$ into each well and maintained for $2 \mathrm{~h}$ at $37^{\circ} \mathrm{C}$. The medium containing CCK-8 was removed and added into another well. The absorbance at $450 \mathrm{~nm}$ was detected in each well using a microplate reader (Bio-Rad Laboratories, Inc.).
Statistical analysis. All experiments were repeated three times. All data were analyzed using GraphPad Prism (version 7.0; GraphPad Software, Inc.). Data are presented as the mean \pm SD. Differences between two groups were compared using a paired or unpaired Student's t-test. Differences among three groups were calculated using one-way ANOVA followed by Newman-Keuls test. Pearson's correlation analysis was used to analyze the correlation between miR-138-5p and CDK8. $\mathrm{P}<0.05$ was considered to indicate a statistically significant difference.

\section{Results}

miR-138-5p is downregulated in NSCLC tissues and cell lines. To investigate the potential biological function of miR-138-5p in NSCLC, miR-138-5p expression was measured in 30 pairs of tumor tissues and normal tissues from 30 patients with NSCLC. RT-qPCR results showed that miR-138-5p levels were significantly decreased in tumor tissues compared with normal tissues (Fig. 1A). Subsequently, miR-138-5p levels were analyzed in normal epithelial lung cell line BEAS-2B and three NSCLC cell lines, including A549, H358 and H1299. In comparison with BEAS-2B, miR-138-5p expression was significantly lower in the three NSCLC cell lines tested (Fig. 1B). CDK8 mRNA expression was increased in tumor tissues compared with matched normal tissues (Fig. 1C). There was an inverse correlation between miR-138-5p and CDK8 
A

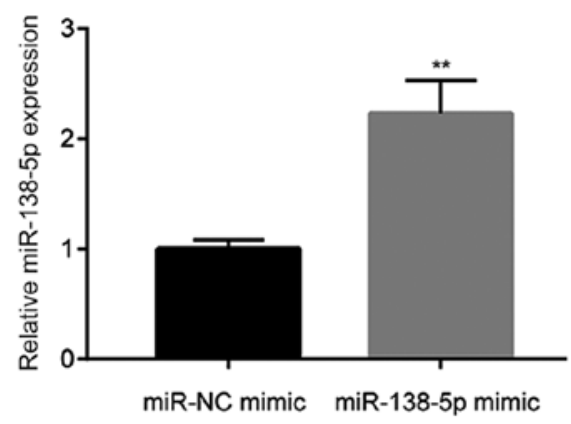

C

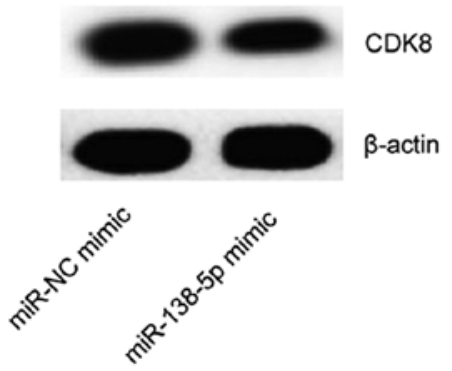

B

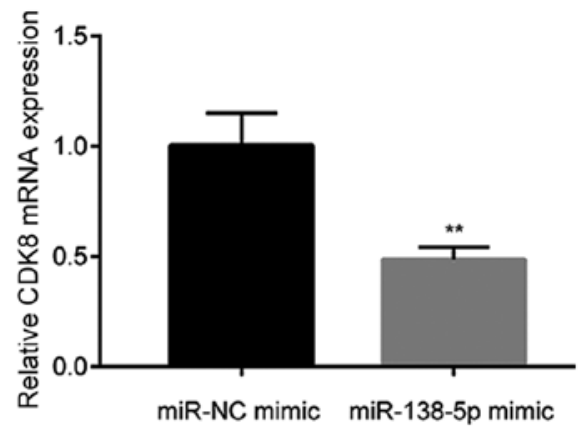

D

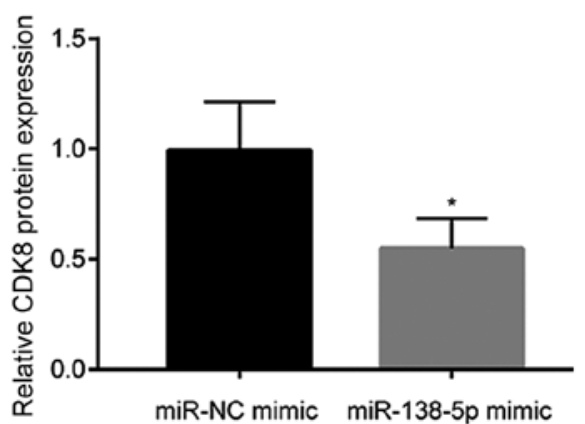

Figure 2. miR-138-5p represses CDK8 expression in A549 cells. (A) Transfection of miR-138-5p mimic increased miR-138-5p expression in A549 cells. (B) Transfection of miR-138-5p mimic decreased CDK8 mRNA expression in A549 cells. (C) miR-138-5p overexpression decreased CDK8 protein levels in A549 cells. (D) Quantification of CDK8 protein expression level. ${ }^{*} \mathrm{P}<0.05,{ }^{* *} \mathrm{P}<0.01$ vs. miR-NC mimic. miR, microRNA; NC, negative control.

(Fig. 1D). The present findings suggested that miR-138-5p may be associated with CDK8 and may play a role in NSCLC.

miR-138-5p negatively regulates CDK8 in NSCLC cells. CDK8 was upregulated in NSCLC tissues. To evaluate whether miR-138-5p regulated CDK8 expression, miR-138-5p mimic was transfected into A549 cells. Transfection of miR-138-5p mimic increased miR-138-5p level in A549 cells (Fig. 2A). In addition, miR-138-5p mimic significantly reduced CDK8 mRNA level (Fig. 2B). Furthermore, western blot analysis indicated that $\mathrm{CDK} 8$ protein levels were also decreased following miR-138-5p overexpression (Fig. 2C and D).

$C D K 8$ is a target gene of miR-138-5p. To further investigate whether CDK8 was a target gene of miR-138-5p, TargetScan was used to predict the interaction between miR-138-5p and CDK8 3'UTR. Bioinformatic analysis indicated that there was a complementary binding site between miR-138-5p and the 3'UTR of CDK8 mRNA (Fig. 3A). To determine their direct binding, a portion of the 3'UTR of CDK8 mRNA was inserted into a firefly luciferase reporter. A dual luciferase assay was performed, and miR-138-5p mimic decreased the relative luciferase activity of cells transfected with CDK8 3'UTR-WT, whereas luciferase activity was not changed in cells transfected with CDK8 3'UTR-Mut and miR-138-5p mimic compared with cells transfected with CDK8 3'UTR-Mut and miR-NC (Fig. 3B). Collectively, the present results indicated that CDK8 was directly regulated by miR-138-5p in NSCLC cells.

Overexpression of miR-138-5p inhibits NSCLC cell proliferation by regulating $C D K 8$. The function of $\mathrm{miR}-138-5 \mathrm{p}$ in NSCLC cells was examined. A pcDNA3.1 plasmid expressing CDK8 was transfected into A549 cells to increase CDK8 expression. Using RT-qPCR, CDK8 mRNA level was identified to be increased following pcDNA3.1-CDK8 transfection (Fig. 4A). Using RT-qPCR and western blot analysis, miR-138-5p mimic was found to decrease CDK8 mRNA and protein level, which could be recovered following pcDNA3.1-CDK8 transfection (Fig. 4B-D). Cell proliferation was investigated, and overexpression of miR-138-5p inhibited cell proliferation of A549 cells, whereas transfection of pcDNA3.1-CDK8 partially reversed the cell proliferation inhibition induced by miR-138-5p (Fig. 4E).

Overexpression of $\mathrm{miR}-138-5 \mathrm{p}$ influences cell cycle and cell apoptosis by regulating $C D K 8$. CDK8 is a major regulator of cell cycle (13). Using flow cytometry, miR-138-5p mimic was found to induce an accumulation of cells in G0/G1 phase. In addition, overexpression CDK8 reduced the number of cells in $\mathrm{G} 0 / \mathrm{G} 1$ phase (Fig. 5A and B). A cell apoptosis assay was performed, and transfection of miR-138-5p significantly increased cell apoptosis rate, whereas CDK8 overexpression partially reversed cell apoptosis (Fig. 5C and D). The present results suggested that miR-138-5p promoted cell cycle arrest and cell apoptosis by repressing CDK8 expression in NSCLC cells.

\section{Discussion}

NSCLC is a major type of lung cancer, and is one of most lethal cancer types worldwide (17). Previous studies identified that many miRNAs serve critical roles in cancer progression $(18,19)$. In cancer cells, miRNAs can act as oncogenes or tumor 

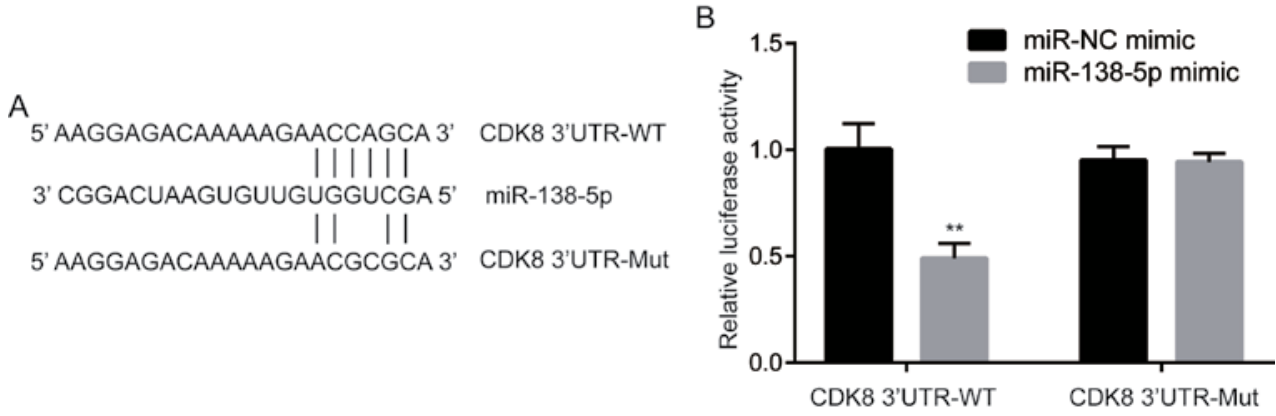

Figure 3. CDK8 is a target gene of miR-138-5p in A549 cells. (A) Sequence alignment showing a complementary binding site between CDK8 3'UTR and miR-138-5p. (B) Dual luciferase reporter assay showed that overexpression of miR-138-5p reduced the relative luciferase activity in A549 cells transfected with CDK8 3'UTR-WT. ${ }^{* *} \mathrm{P}<0.01$ vs. miR-NC mimic. UTR, untranslated region; miR, microRNA; NC, negative control; WT, wild-type; Mut, mutant.
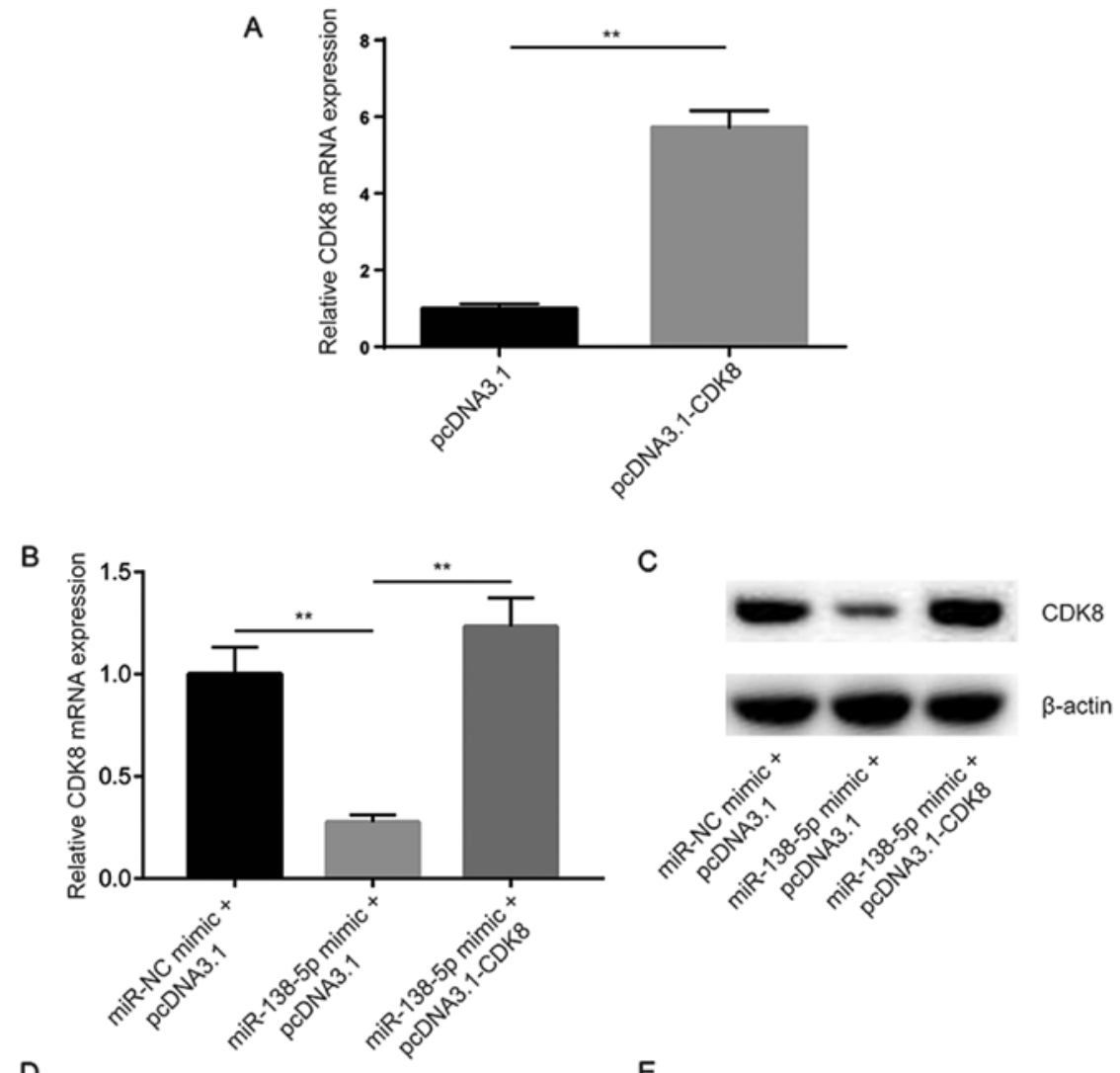

D

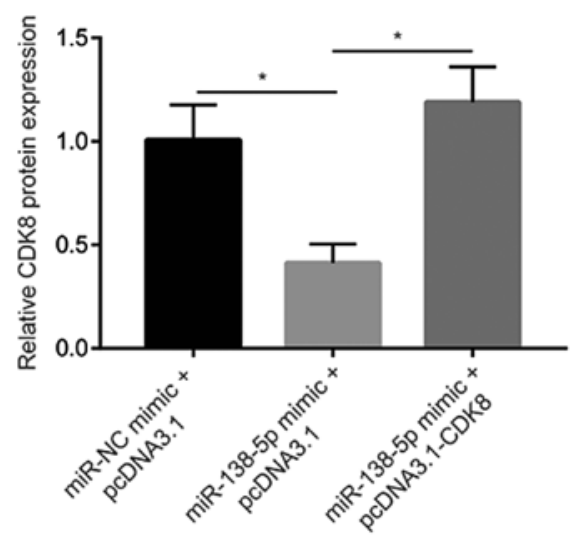

E

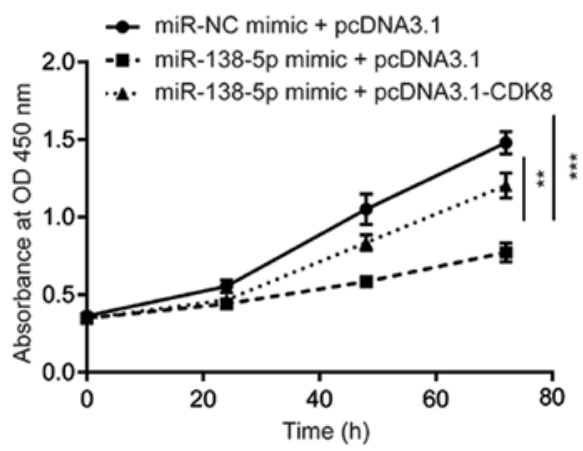

Figure 4. miR-138-5p inhibits A549 cell proliferation by regulating CDK8. (A) Transfection of pcDNA3.1-CDK8 increased CDK8 mRNA level, as assessed by reverse transcription-quantitative PCR analysis. (B) Transfection of miR-138-5p mimic decreased CDK8 mRNA level and this effect could be reversed by concomitant CDK8 overexpression in A549 cells. (C) Western blot analysis suggested that transfection of miR-138-5p mimic decreased CDK8 protein level and this effect could be reversed by concomitant CDK8 overexpression in A549 cells. (D) Quantitative analysis of CDK8 protein expression. (E) miR-138-5p mimic inhibited A549 cell proliferation and this effect was reversed by overexpression of CDK8. ${ }^{*} \mathrm{P}<0.05,{ }^{* *} \mathrm{P}<0.01,{ }^{* * * *} \mathrm{P}<0.001$. miR, microRNA; OD, optical density; NC, negative control. 
A

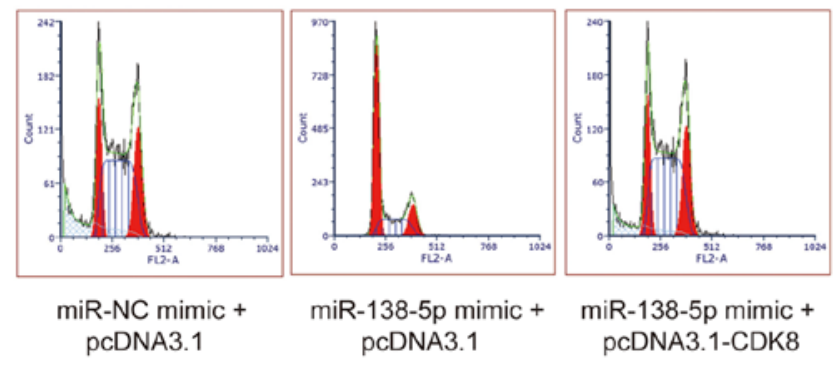

C
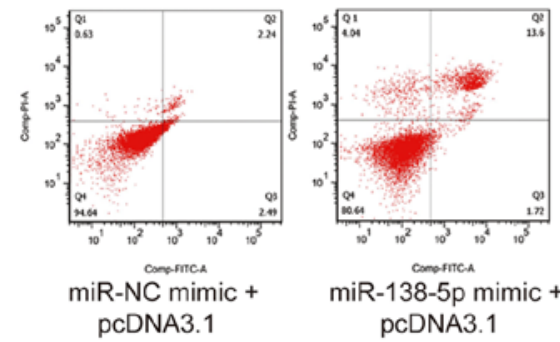

miR-138-5p mimic + pcDNA3.1
B

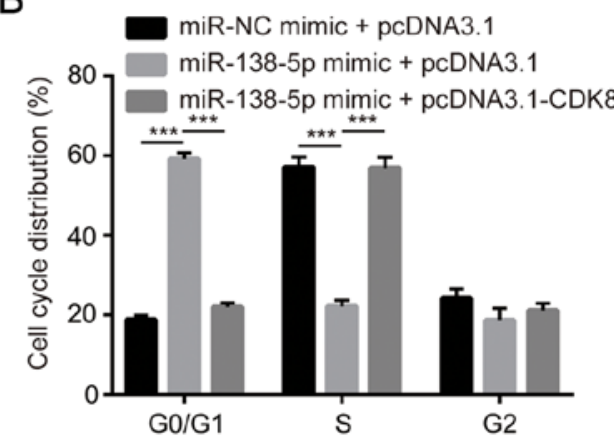

$\mathrm{D}$

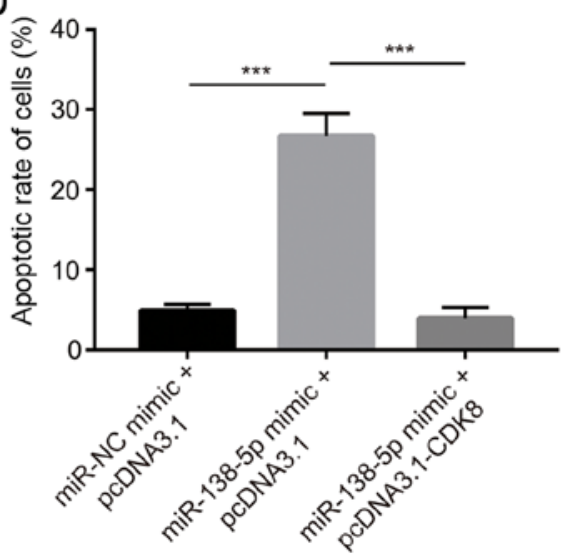

Figure 5. miR-138-5p overexpression induces cell cycle arrest in G0/G1 and cell apoptosis by repressing CDK8. (A) miR-138-5p mimic transfection led to accumulation of A549 cells in G0/G1 phase and this effect was reversed by CDK8 overexpression. (B) Quantitative analysis of cell cycle distribution. (C) Overexpression of miR-138-5p significantly increased the cell apoptotic rate and this effect was reversed by CDK8 overexpression in A549 cells. (D) Quantitative analysis of cell apoptotic rate. ${ }^{* * *} \mathrm{P}<0.001$. miR, microRNA; PI, propidium iodide; NC, negative control.

suppressors (20). In addition, several miRNAs were identified as good prognostic predictors in patients with NSCLC $(21,22)$.

Accumulating evidence showed that miR-138-5p is a tumor suppressor in many cancer types, including bladder and colorectal cancer $(23,24)$. In NSCLC, microarray screening identified that miR-138-5p is significantly downregulated in gefitinib-resistant NSCLC cells compared with parental cells and may regulate gefitinib sensitivity by regulating $\mathrm{G}$ protein-coupled receptor 124 (12). However, whether and how miR-138-5p may be involved in cell proliferation, cell cycle and cell apoptosis remain unclear. In the present study, RT-qPCR results suggested that miR-138-5p was decreased in NSCLC tumor tissues compared with matched normal tissues. Additionally, a decreased expression of miR-138-5p was observed in NSCLC cell lines compared with normal epithelial lung cell line BEAS-2B. More importantly, overexpression of miR-138-5p induced cell proliferation arrest, cell apoptosis and increased the number of cells in G0/G1 phase. The present data suggested that miR-138-5p may serve as a tumor suppressor gene in NSCLC.

CDK8 is a well-characterized oncogene in various cancer types $(25,26)$. Several reports showed that the downregulation of various miRNAs contribute to the upregulation of CDK8 in cancer cells $(27,28)$. In NSCLC, miR-10a targets CDK8, regulating cisplatin chemosensitivity (29). The present bioinformatic analysis indicated that miR-138-5p may bind to the 3'UTR of CDK8 mRNA. In addition, overexpression of miR-138-5p decreased CDK8 expression in A549 cells.
Moreover, dual luciferase assay confirmed that CDK8 was a target gene of miR-138-5p. CDK8 is a regulator of cell cycle, and alteration of CDK8 activity or expression was identified to influence cell cycle, leading to cell apoptosis and cell proliferation arrest $(30,31)$. In the present study, miR-138-5p mimic was found to induce cell growth arrest, increasing the number of cells in G0/G1 phase and increasing the cell apoptotic rate. Moreover, transfection of CDK8 partially reversed the effects of miR-138-5p overexpression on cell proliferation inhibition, cell cycle redistribution and cell apoptosis increase. Therefore, the present study suggested that the downregulation of miR-138-5p may be responsible for the upregulation of CDK8 in NSCLC, and miR-138-5p was found to inhibit NSCLC cell proliferation by regulating cell cycle and cell apoptosis.

Collectively, miR-138-5p was found to be downregulated in NSCLC tumor tissues and inhibited NSCLC cell proliferation by directly targeting CDK8. The present results suggested miR-138-5p may be a promising therapeutic target for treating patients with NSCLC.

However, the present study presented certain limitations; since miR-138-5p was downregulated in NSCLC tumor tissues, the effects of miR-138-5p overexpression were investigated to examine whether miR-138-5p mimics could reverse the abnormal phenotype of NSCLC. Therefore, further studies are required to investigate the effect of miR-138-5p inhibition. In addition, the present study did not investigate the effects of CDK8 on the regulation of $\beta$-catenin activity, Notch signaling and on additional downstream effectors of CDK8. Moreover, 
the role of miR-138-5p on cell migration and invasion were not examined in the present study, and further studies are required to investigate these aspects.

\section{Acknowledgements}

Not applicable.

\section{Funding}

No funding was received.

\section{Availability of data and materials}

The datasets used during the present study are available from the corresponding author upon reasonable request.

\section{Authors' contributions}

FT conceived the study, analyzed the data, and wrote the manuscript. SX, QX, XF, and SW carried out the experiments and analyzed the data.

\section{Ethics approval and consent to participate}

Ethical approval was obtained for the use of human tissues prior to the start of the study from an Ethics Committee based at The Central Hospital of Linyi.

\section{Patient consent for publication}

Each patient provided written consent for publication.

\section{Competing interests}

The authors declare that they have no competing interests.

\section{References}

1. Torre LA, Bray F, Siegel RL, Ferlay J, Lortet-Tieulent J and Jemal A: Global cancer statistics, 2012. CA Cancer J Clin 65: 87-108, 2015.

2. Heist RS and Engelman JA: SnapShot: Non-small cell lung cancer. Cancer Cell 21: e448 e442, 2012.

3. Auperin A, Le Pechoux C, Rolland E, Curran WJ, Furuse K, Fournel P, Belderbos J, Clamon G, Ulutin HC, Paulus R, et al: Meta-analysis of concomitant versus sequential radiochemotherapy in locally advanced non-small-cell lung cancer. J Clin Oncol 28: 2181-2190, 2010.

4. Bartel DP: MicroRNAs: Genomics, biogenesis, mechanism, and function. Cell 116: 281-297, 2004.

5. Bartel DP: MicroRNAs: Target recognition and regulatory functions. Cell 136: 215-233, 2009.

6. Zhao Y and Srivastava D: A developmental view of microRNA function. Trends Biochem Sci 32: 189-197, 2007.

7. Hao J, Zhao S, Zhang Y, Zhao Z, Ye R, Wen J and Li J: Emerging role of microRNAs in cancer and cancer stem cells. J Cell Biochem 115: 605-610, 2014.

8. Raponi M, Dossey L, Jatkoe T, Wu X, Chen G, Fan H and Beer DG: MicroRNA classifiers for predicting prognosis of squamous cell lung cancer. Cancer Res 69: 5776-5783, 2009.

9. Mitomo S, Maesawa C, Ogasawara S, Iwaya T, Shibazaki M, Yashima-Abo A, Kotani K, Oikawa H, Sakurai E, Izutsu N, et al: Downregulation of miR-138 is associated with overexpression of human telomerase reverse transcriptase protein in human anaplastic thyroid carcinoma cell lines. Cancer Sci 99: 280-286, 2008.
10. Ding J, Yeh CR, Sun Y, Lin C, Chou J, Ou Z, Chang C, Qi J and Yeh S: Estrogen receptor $\beta$ promotes renal cell carcinoma progression via regulating LncRNA HOTAIR-miR-138/200c/204/217 associated CeRNA network. Oncogene 37: 5037-5053, 2018.

11. Peng J, Hou F, Feng J, Xu SX and Meng XY: Long non-coding RNA BCYRN1 promotes the proliferation and metastasis of cervical cancer via targeting microRNA-138 in vitro and in vivo. Oncol Lett 15: 5809-5818, 2018.

12. Gao Y, Fan X, Li W, Ping W, Deng Y and Fu X: miR-138-5p reverses gefitinib resistance in non-small cell lung cancer cells via negatively regulating $G$ protein-coupled receptor 124 . Biochem Biophys Res Commun 446: 179-186, 2014.

13. Vermeulen K, Van Bockstaele DR and Berneman ZN: The cell cycle: A review of regulation, deregulation and therapeutic targets in cancer. Cell Prolif 36: 131-149, 2003.

14. Malumbres $\mathrm{M}$ and Barbacid M: Cell cycle, CDKs and cancer: A changing paradigm. Nat Rev Cancer 9: 153-166, 2009.

15. Nakamura A, Nakata D, Kakoi Y, Kunitomo M, Murai S, Ebara S, Hata A and Hara T: CDK8/19 inhibition induces premature G1/S transition and ATR-dependent cell death in prostate cancer cells. Oncotarget 9: 13474-13487, 2018.

16. Livak KJ and Schmittgen TD: Analysis of relative gene expression data using real-time quantitative PCR and the 2(-Delta Delta C(T)) method. Methods 25: 402-408, 2001.

17. Molina JR, Yang P, Cassivi SD, Schild SE and Adjei AA: Non-small cell lung cancer: Epidemiology, risk factors, treatment, and survivorship. Mayo Clin Proc 83: 584-594, 2008.

18. Zhu C, Zhao Y, Zhang Z, Ni Y, Li X and Yong H: MicroRNA-33a inhibits lung cancer cell proliferation and invasion by regulating the expression of $\beta$-catenin. Mol Med Rep 11: 3647-3651, 2015.

19. Zhang Z, Zhang Y, Sun XX, Ma X and Chen ZN: microRNA-146a inhibits cancer metastasis by downregulating VEGF through dual pathways in hepatocellular carcinoma. Mol Cancer 14: 5 , 2015.

20. Zhang B, Pan X, Cobb GP and Anderson TA: microRNAs as oncogenes and tumor suppressors. Dev Biol 302: 1-12, 2007.

21. Lu G, Fu D, Jia C, Chai L, Han Y, Liu J, Wu T, Xie R, Chang Z, Yang H, et al: Reduced miR-105-1 levels are associated with poor survival of patients with non-small cell lung cancer. Oncol Lett 14: 7842-7848, 2017.

22. Li Y, Zhang H, Dong Y, Fan Y, Li Y, Zhao C, Wang C, Liu J, Li X, Dong M, et al: MiR-146b-5p functions as a suppressor miRNA and prognosis predictor in non-small cell lung cancer. J Cancer 8: 1704-1716, 2017.

23. Yang R, Liu M, Liang H, Guo S, Guo X, Yuan M, Lian H, Yan X, Zhang S, Chen X, et al: miR-138-5p contributes to cell proliferation and invasion by targeting Survivin in bladder cancer cells. Mol Cancer 15: 82, 2016.

24. Zhao L, Yu H, Yi S, Peng X, Su P, Xiao Z, Liu R, Tang A, Li X, Liu $F$ and Shen S: The tumor suppressor miR-138-5p targets PD-L1 in colorectal cancer. Oncotarget 7: 45370-45384, 2016.

25. Serrao A, Jenkins LM, Chumanevich AA, Horst B, Liang J, Gatza ML, Lee NY, Roninson IB, Broude EV and Mythreye K: Mediator kinase CDK8/CDK19 drives YAP1-dependent BMP4-induced EMT in cancer. Oncogene 37: 4792-4808, 2018.

26. Philip S, Kumarasiri M, Teo T, Yu M and Wang S: Cyclin-dependent kinase 8: A new hope in targeted cancer therapy? J Med Chem 61: 5073-5092, 2018.

27. Luo Q, Zhang Z, Dai Z, Basnet S, Li S, Xu B and Ge H: Tumor-suppressive microRNA-195-5p regulates cell growth and inhibits cell cycle by targeting cyclin dependent kinase 8 in colon cancer. Am J Transl Res 8: 2088-2096, 2016.

28. Li M, Tian L, Ren H, Chen X, Wang Y, Ge J, Wu S, Sun Y, Liu M and Xiao H: MicroRNA-101 is a potential prognostic indicator of laryngeal squamous cell carcinoma and modulates CDK8. J Transl Med 13: 271, 2015.

29. Zhang Z, Zhang L, Yin ZY, Fan XL, Hu B, Wang LQ and Zhang D: miR-107 regulates cisplatin chemosensitivity of A549 non small cell lung cancer cell line by targeting cyclin dependent kinase 8. Int J Clin Exp Pathol 7: 7236-7241, 2014.

30. Liu ZJ, Ueda T, Miyazaki T, Tanaka N, Mine S, Tanaka Y, Taniguchi T, Yamamura H and Minami Y: A critical role for cyclin $\mathrm{C}$ in promotion of the hematopoietic cell cycle by cooperation with c-Myc. Mol Cell Biol 18: 3445-3454, 1998.

31. He SB, Yuan Y, Wang L, Yu MJ, Zhu YB and Zhu XG: Effects of cyclin-dependent kinase 8 specific siRNA on the proliferation and apoptosis of colon cancer cells. J Exp Clin Cancer Res 30: 109, 2011. 